\title{
PEMODELAN INFLASI BERDASARKAN HARGA-HARGA PANGAN MENGGUNAKAN SPLINE MULTIVARIABEL
}

\author{
Alan Prahutama ${ }^{1}$, Tiani Wahyu $\mathbf{U}^{2}$, Rezzy Eko $\mathbf{C}^{3}$, Dede Zumrohtuliyosi ${ }^{3}$ \\ ${ }^{1}$ Dosen Jurusan Statistika FSM Undip, alanprahutama@undip.ac.id \\ ${ }^{2}$ Dosen Jurusan Statistika Unimus \\ ${ }^{3}$ Mahasiswa Jurusan Statistika FSM Undip
}

\begin{abstract}
Inflation is defined as a sustained increase in the general level of price for goods and services. Some of the events that led to inflation in Indonesia is rising fuel prices, rising prices of meat and chili. Inflation has negative impact, because decreased purchasing power. So that the inflation model is needed. Modeling inflation can be use regression models. The approach can be performed with nonparametric regression, one of method of nonparametric regression is spline method. In this case, use three predictors to modeling inflation using spline multivariable. The predictors are price of rice, price of chicken, and price of chili. Obtained multivariable spline models with R-square of 93.94\% with optimal $m=2$ (quadratic) for 1 knots.
\end{abstract}

Keywords: Spline Multivariable, GCV, Inflation

\section{Pendahuluan}

Inflasi diartikan sebagai meningkatnya harga-harga secara umum dan terus menerus $^{[5]}$. Kenaikan harga dari satu atau dua barang belum bisa dikatakan inflasi, kecuali kenaikan tersebut meluas. Terjadi peningkatan inflasi akan menyebabkan penurunan pertumbuhan perekonomian suatu negara. Misalnya kenaikan BBM menyebabkan inflasi, karena dengan kenaikan BBM harga-harga barang meningkat, daya beli masyarakat menurun dan biaya produksi meningkat. Salah satu faktor yang mempengaruhi inflasi adalah komoditas harga bahan pangan ${ }^{[9]}$.

Salah satu metode statistika yang bisa menjelaskan hubungan antara antara variabel prediktor terhadap variabel respon adalah analisis regresi. Analisis regresi yang sering digunakan adalah analisis regresi parametrik. Pendekatan regresi secara parametrik membutuhkan asumsi-asumsi yang harus dipenuhi untuk menghasilkan pemodelan yang baik $^{[4]}$. Pendekatan regresi parametrik menghasilkan model yang baik jika bentuk kurva regresinya diketahui. Regresi nonparametrik digunakan jika bentuk kurva fungsinya tidak diketahui sehingga data akan mencari sendiri bentuk kurva regresinya ${ }^{[1]}$. Pendekatan regresi nonparametrik yang sudah berkembang antara lain dengan deret Fourier, Polinomial lokal, kernel, dan spline.

Spline merupakan polinomial truncated, yaitu bentuk kurva yang terpotong-potong sehingga spline mampu mengatasi perubahan data pada sub interval tertentu. Pendekatan spline menggunkan Penalized Least Square yaitu dengan mencari bentuk kurva dari regresi sehingga model spline memiliki fleksibelitas yang tinggi ${ }^{[7]}$. Penelitian menggunakan pendekatan spline sudah banyak dilakukan antara lain Wang ${ }^{[8]}$ melakukan penelitian dengan pendekatan spline dengan titik-titik knot. Erifandi ${ }^{[2]}$ melakukan pendekatan spline birespon. Salah satu prosedur pemodelan menggunakan spline adalah menentukan titik knot optimum. Salah satu penentuan titik knot optimum adalah dengan menggunakan Generalized Cross Validation (GCV) ${ }^{[1]}$.

Berdasarkan uraian-urain tersebut, penelitian ini bertujuan untuk mengembangkan model spline pada data perubahan inflasi di Jawa Tengah. Suparti ${ }^{[6]}$ mengembangkan 
model inflasi di Indonesia menggunakan Spline berdasarkan waktu. Jawa Tengah merupakan salah satu provinsi yang menghasilkan produksi bahan pangan yang surplus, khususnya beras. Model yang dikembangkan adalah pengaruh perubahan harga bahan makanan antara lain perubahan harga beras, daging ayam, cabe rawit dan tanaman sayur sebagai variabel-variabel prediktor, terhadap perubahan nilai inflasi di Jawa Tengah sebagai variabel respon. Hal ini dikarenakan inflasi dihitung berdasarkan indeks harga konsumen (IHK), sehigga variable-variabel prediktor tersebut diharapkan mampu mengukur nilai dari IHK ${ }^{[9]}$. Jika diketahui perubahan inflasi pada suatu periode maka akan diketahui nilai inflasi pada periode tersebut. Pendekatan spline yang digunakan untuk memodelkan nilai inflasi adalah dengan pendekatan linier, kuadratik dan kubik. Kemudian dari model yang didapat, diharapkan mampu meramalkan nilai inflasi di Jawa Tengah pada periode berikutnya.

\section{Tinjauan Pustaka}

\subsection{Regresi Parametrik}

Regresi parametrik merupakan pendekatan regresi untuk mengetahui pola hubungan antara variabel respon dan variabel prediktor dengan bentuk kurva regresi diketahui. Persamaan model regresi linier sederhana sebagai berikut ${ }^{[3]}$ :

$$
y_{i}=\beta_{0}+\beta_{1} X_{i}+\varepsilon_{i}, i=1,2, \ldots, n .
$$

Jika ditulis dalam bentuk matriks diperoleh model regresi:

$$
\mathbf{y}=\mathbf{X} \boldsymbol{\beta}+\boldsymbol{\varepsilon}, \operatorname{dimana} \boldsymbol{\varepsilon} \sim N\left(\mathbf{0}, \boldsymbol{\sigma}^{2} \mathbf{I}\right) .
$$

Estimasi koefisien regresi $\boldsymbol{\beta}$ dilakukan dengan menggunakan OLS (Ordinary Least Square). Metode ini dilakukan dengan meminimumkan $\boldsymbol{\varepsilon}^{\mathbf{T}} \boldsymbol{\varepsilon}$ terhadap $\boldsymbol{\beta}$. Nilai $\boldsymbol{\varepsilon}^{\mathbf{T}} \boldsymbol{\varepsilon}=(\mathbf{y}-\mathbf{X} \boldsymbol{\beta})^{\mathbf{T}}(\mathbf{y}-\mathbf{X} \boldsymbol{\beta})$, diturunkan terhadap $\boldsymbol{\beta}$ maka didapat estimator

$$
\hat{\boldsymbol{\beta}}=\left(\mathbf{X}^{\mathbf{T}} \mathbf{X}\right)^{-1} \mathbf{X}^{\mathbf{T}} \mathbf{y} \text {. }
$$

\subsection{Spline}

Spline merupakan suatu polinomial dimana segmen-segmen polinomial yang berbeda digabungkan bersama pada knots $k_{1}, k_{2}, \ldots, k_{\mathrm{r}}$ dan kontinu sehingga bersifat fleksibel dibandingkan polinomial biasa. Spline orde m dengan titik-titik knot $k_{1}, k_{2}, \ldots, k_{\mathrm{r}}$ secara umum dapat disajikan dalam bentuk ${ }^{[3]}$ :

$$
y_{i}=S(x)+\varepsilon_{i} \text { untuk } S(x)=\sum_{i=1}^{m} \beta_{i} x^{i}+\sum_{j=1}^{r} \beta_{j+m}\left(x-k_{j}\right)_{+}^{m}
$$

dengan $\left(x-k_{j}\right)_{+}^{m}=\left\{\begin{array}{cc}\left(x-k_{j}\right)^{m} & , x \geq k_{j} \\ 0 & , x<k_{j}\end{array}\right.$

dimana $\beta$ adalah konstanta dan $k_{1}, k_{2}, \ldots, k_{\mathrm{r}}$ adalah titik-titik knots, sehingga jika dibuat bentuk matriks sebagai berikut:

$$
\left(\begin{array}{c}
y_{1} \\
y_{2} \\
\vdots \\
y_{n}
\end{array}\right)=\left(\begin{array}{cccccc}
1 & \cdots & x_{1}^{m} & \left(x_{1}-k_{1}\right)^{m} & \cdots & \left(x_{1}-k_{r}\right)^{m} \\
\vdots & \vdots & \vdots & \vdots & \vdots & \vdots \\
1 & \cdots & x_{n}^{m} & \left(x_{n}-k_{1}\right)^{m} & \cdots & \left(x_{n}-k_{r}\right)^{m}
\end{array}\right)\left(\begin{array}{c}
\beta_{0} \\
\vdots \\
\beta_{m-1} \\
\beta_{m} \\
\vdots \\
\beta_{r}
\end{array}\right)+\left(\begin{array}{c}
\varepsilon_{1} \\
\varepsilon_{2} \\
\vdots \\
\varepsilon_{n}
\end{array}\right)
$$

atau $\quad \mathbf{y}=\mathbf{X} \boldsymbol{\beta}+\boldsymbol{\varepsilon}$ 
Estimasi model spline menggunakan Weighted Least Square (WLS) menghasilkan estimasi sebagai berikut:

$$
\hat{\boldsymbol{\beta}}=\left(\mathbf{X}^{\mathrm{T}} \mathbf{W X}\right)^{-1} \mathbf{X}^{\mathrm{T}} \mathbf{W} \mathbf{y},
$$

dengan $\mathbf{W}$ merupakan matriks diagonal dari perhitungan estimasi bobot. Sehingga model estimasinya didapat:

$$
\hat{\mathbf{y}}=\mathbf{X}\left(\mathbf{X}^{\mathbf{T}} \mathbf{W X}\right)^{-1} \mathbf{X}^{\mathbf{T}} \mathbf{W} \mathbf{y} \quad \text { atau } \quad \hat{\mathbf{y}}=\mathbf{A}(k) \mathbf{y} .
$$

Model Spline orde $m=1$ (Linier) dengan 1 titik knot untuk 3 prediktor adalah sebagai berikut:

$$
y_{i}=a_{0}+a_{11} x_{1 i}+b_{11}\left(x_{1 i}-K_{11}\right)_{+}^{1}+a_{12} x_{2 i}+b_{12}\left(x_{2 i}-K_{12}\right)_{+}^{1}+a_{13} x_{3 i}+b_{13}\left(x_{3 i}-K_{13}\right)_{+}^{1}+\varepsilon
$$

Model Spline orde $m=2$ (kuadratik) dengan 1 titik knot untuk 3 prediktor adalah sebagai berikut $^{[6]}$ :

$$
\begin{aligned}
y_{i}= & a_{0}+a_{11} x_{1 i}+b_{11}\left(x_{1 i}-K_{11}\right)_{+}^{1}+a_{21} x_{1 i}^{2}+b_{11}\left(x_{1 i}-K_{11}\right)_{+}^{2}+a_{12} x_{2 i}+b_{12}\left(x_{2 i}-K_{12}\right)_{+}^{1} \\
& +a_{22} x_{2 i}^{2}+b_{12}\left(x_{2 i}-K_{12}\right)_{+}^{2}+a_{13} x_{3 i}+b_{13}\left(x_{3 i}-K_{13}\right)_{+}^{1}+a_{23} x_{3 i}^{2}+b_{13}\left(x_{3 i}-K_{13}\right)_{+}^{2}+\varepsilon
\end{aligned}
$$

Model Spline orde $\mathrm{m}=1$ dengan 2 titik knot untuk 3 prediktor adalah sebagai berikut:

$$
\begin{aligned}
y_{i}= & a_{0}+a_{11} x_{1 i}+b_{11}\left(x_{1 i}-K_{11}\right)_{+}^{1}+b_{21}\left(x_{1 i}-K_{21}\right)_{+}^{1}+a_{12} x_{2 i}+b_{12}\left(x_{2 i}-K_{12}\right)_{+}^{1}+b_{22}\left(x_{2 i}-K_{22}\right)_{+}^{1}+ \\
& a_{13} x_{3 i}+b_{13}\left(x_{3 i}-K_{13}\right)_{+}^{1}+b_{23}\left(x_{3 i}-K_{23}\right)_{+}^{1}+\varepsilon
\end{aligned}
$$

Model Spline orde $m=2$ dengan 2 titik knot untuk 3 prediktor adalah sebagai berikut:

$$
\begin{aligned}
y_{i}= & a_{0}+a_{11} x_{1 i}+b_{11}\left(x_{1 i}-K_{11}\right)_{+}^{1}+a_{21} x_{1 i}^{2}+b_{11}\left(x_{1 i}-K_{21}\right)_{+}^{2}+a_{12} x_{2 i}+b_{12}\left(x_{2 i}-K_{12}\right)_{+}^{1} \\
& +a_{22} x_{2 i}^{2}+b_{12}\left(x_{2 i}-K_{22}\right)_{+}^{2}+a_{13} x_{3 i}+b_{13}\left(x_{3 i}-K_{13}\right)_{+}^{1}+a_{23} x_{3 i}^{2}+b_{13}\left(x_{3 i}-K_{23}\right)_{+}^{2}+\varepsilon
\end{aligned}
$$

\subsection{Generalized Cross Validation}

Terdapat beberapa metode untuk memilih titik knot, salah satunya adalah dengan menggunakan metode Generalized Cross Validation (GCV). GCV didefinisikan sebagai berikut:

dengan : $\operatorname{MSE}(k)=n^{-1} \sum_{i=1}^{n}\left\{y_{i}-\hat{f}\left(t_{i}\right)\right\}^{2}$.

$\mathbf{A}(\mathrm{k})$ : matrik proyeksi pada titik knot ke-k

$\mathrm{y}_{\mathrm{i}} \quad$ : variabel respon ke-i

I : matrik identitas

Pada saat orde $(m)$ spline tinggi, knot yang banyak dan knot yang terlalu dekat akan membentuk matriks dalam perhitungan yang mendekati singular, sehingga persamaan tidak dapat diselesaikan. Pemilihan titik knot optimal dilakukan dengan melihat nilai GCV yang minimum $^{[3]}$.

\section{Metodologi Penelitian}

Variabel respon yang digunakan pada penelitian ini adalah perubahan nilai inflasi di Jawa Tengah tahun $2013(Y)$. Sedangkan variabel prediktornya antara lain Perubahan harga beras $\left(\mathrm{X}_{1}\right)$, Perubahan harga daging ayam $\left(\mathrm{X}_{2}\right)$, Perubahan harga cabai rawit $\left(\mathrm{X}_{3}\right)$, Perubahan harga tanaman sayur $\left(\mathrm{X}_{4}\right)$ di kota Semarang pada Tahun 2013 oleh Bank Indonesia. Melakukan pendekatan regresi nonparametrik dengan regresi Spline dengan langkah-langkah sebagai berikut:

1. Mendapatkan nilai bandwidth untuk setiap variabel prediktor secara simultan

2. Memodelkan regresi Spline Linier $(m=1)$ 
3. memodelkan regresi Spline Kuadratik $(m=2)$

4. Mendapatkan nilai $R^{2}$ untuk masing-masing model

\section{Hasil Dan Pembahasan}

Berdasarkan Gambar 1 terlihat scatterplot antara variabel dependen dengan variabel-variabel independent yang sudah distandardisasi untuk menyamakan satuan. Berdasarkan gambar tersebut terlihat plot data menyebar secara acak, sehingga sesuai dengan pemodelan regresi nonparametrik.
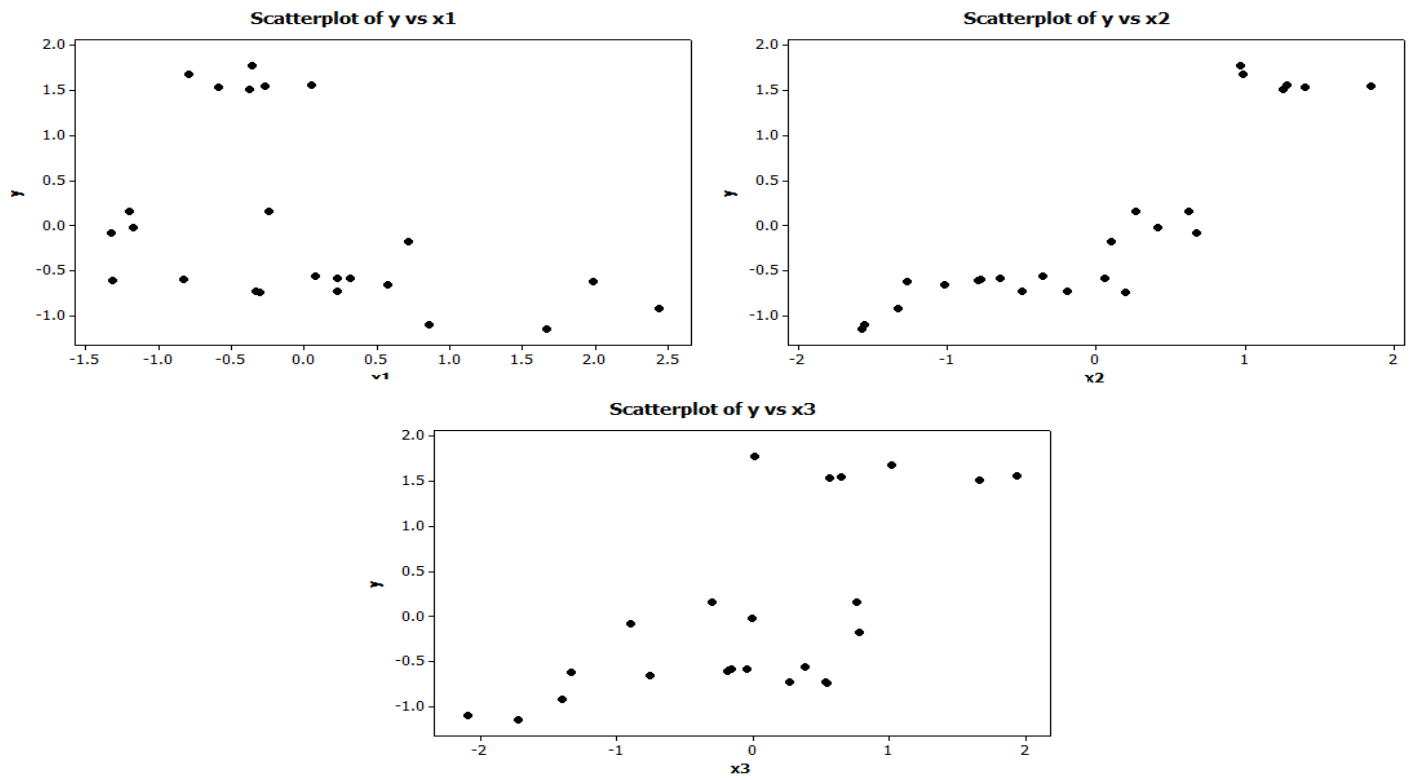

Gambar 1. Scatterplot antara Variabel $y, x_{1}, x_{2}$, dan $x_{3}$

\subsection{Pemodelan Spline Multivariabel dengan 1 titik knot}

Langkah pertama sebelum pemodelan regresi spline multivariabel adalah menentukan nilai titik knot yang optimal. Penentuan nilai titik knot optimal menggunakan metode Generalized Cross Validation (GCV). Tabel 1 menunjukan nilai GCV untuk satu titik knot dengan $m=1$ (linier) dan $m=2$ (kuadratik).

Tabel 1. Nilai GCV untuk Satu Titik Knot dengan $m=1$ dan $m=2$

\begin{tabular}{rccccccc}
\hline \multicolumn{3}{c}{ Satu Titik Knot untuk $m=1$} & \multicolumn{3}{c}{ Satu Titik Knot untuk $m=2$} \\
\hline $\mathbf{X}_{\mathbf{1}}$ & $\mathbf{X}_{\mathbf{2}}$ & $\mathbf{X}_{\mathbf{3}}$ & $\mathbf{G C V}$ & $\mathbf{X}_{\mathbf{1}}$ & $\mathbf{X}_{\mathbf{2}}$ & $\mathbf{X}_{\mathbf{3}}$ & $\mathbf{G C V}$ \\
\hline 0.03 & 0.03 & 0 & 0.1970282 & 1.06 & 1 & 1 & 0.1707476 \\
0.05 & 0.05 & 0 & 0.1986317 & 1.08 & 1 & 1 & 0.1707134 \\
$\mathbf{0 . 0 1}$ & $\mathbf{0}$ & $\mathbf{0 . 0 1}$ & $\mathbf{0 . 1 9 4 5 6 4 2}$ & $\mathbf{1 . 1}$ & $\mathbf{1}$ & $\mathbf{1}$ & $\mathbf{0 . 1 7 0 6 7 8 8}$ \\
0.02 & 0 & 0.02 & 0.1947962 & 1 & 1 & 1 & 0.170844 \\
0.03 & 0 & 0.03 & 0.1950628 & 1.01 & 1.01 & 1 & 0.1733423 \\
0.04 & 0 & 0.04 & 0.1953263 & 1.02 & 1.02 & 1 & 0.1758606 \\
\hline
\end{tabular}

Berdasarkan Tabel 1, nilai titik knot yang optimal merupakan nilai GCV terkecil. Untuk $m=1$ nilai titik knot optimal pada variabel $\mathrm{X}_{1}=0.01 ; \mathrm{X}_{2}=0 ; \mathrm{X}_{3}=0.01$. Sedangkan pada orde $m=2$ nilai titik knot optimal untuk masing-masing variabel adalah $\mathrm{X}_{1}=1.1$; $\mathrm{X}_{2}=\mathrm{X}_{3}=1$. Selanjutnya dengan titik knot optimal akan dicari estimasi parameter untuk model. 
Hasil estimasi parameter untuk $m=2$ dengan 1 titik knot adalah

$$
\begin{aligned}
\hat{y}_{i}= & -0.6122-0.0512 x_{1 i}-0.0406\left(x_{1 i}-0.01\right)_{+}^{1}+0.3828 x_{2 i}+0.1795\left(x_{2 i}-0\right)_{+}^{1}+1.5182 x_{3 i} \\
& -0.2404\left(x_{3 i}-0.01\right)_{+}^{1}
\end{aligned}
$$

dengan R-square $=0.8981$ dan MSE $=0.0976$.

Titik knot optimal untuk orde $m=2$ (kuadratik) pada Tabel 1 adalah $\mathrm{X}_{1}=1.1$;

$\mathrm{X}_{2}=\mathrm{X}_{3}=1$ dengan nilai GCV sebesar 0.1706788 .

Hasil estimasi parameter untuk $m=2$ dengan 1 titik knot adalah

$$
\begin{aligned}
\hat{y}_{i}= & -0.469+0.029 x_{1 i}-0.044\left(x_{1 i}-1.1\right)_{+}^{1}+0.894 x_{1 i}^{2}-0.044\left(x_{1 i}-1.1\right)_{+}^{2}+0.894 x_{2 i}+0.976\left(x_{2 i}-1\right)_{+}^{1} \\
& -0.256 x_{2 i}^{2}+0.2901\left(x_{2 i}-1\right)_{+}^{2}+0.0921 x_{3 i}-4.425\left(x_{3 i}-1\right)_{+}^{1}-0.0455 x_{3 i}^{2}-4.425\left(x_{3 i}-1\right)_{+}^{2}
\end{aligned}
$$

dengan R-Square $=0.9394$ dan $\mathrm{MSE}=0.0581$.

\subsection{Pemodelan Spline Multivariabel dengan 2 titik knot}

Selanjutnya akan dicobakan pemodelan spline multivariabel dengan 2 titik knot.

Tabel 2. Nilai GCV Spline Multivariabel untuk $m=1$ (linier) dengan 2 Titik Knot

\begin{tabular}{ccccccc}
\hline \multicolumn{3}{c}{ Titik Knot ke-1 } & \multicolumn{3}{c}{ Titik Knot ke-2 } & \multirow{2}{*}{ GCV } \\
\cline { 1 - 5 } $\mathbf{X}_{\mathbf{1}}$ & $\mathbf{X}_{\mathbf{2}}$ & $\mathbf{X}_{\mathbf{3}}$ & $\mathbf{X}_{\mathbf{1}}$ & $\mathbf{X}_{\mathbf{2}}$ & $\mathbf{X}_{\mathbf{3}}$ & \\
\hline 1.08 & 1 & 1 & 1 & 1 & 1 & 0.1912417 \\
1.1 & 1 & 1 & 1 & 1 & 1 & 0.1914233 \\
1 & 1 & 1 & 1 & 1 & 1 & 0.170844 \\
$\mathbf{1 . 0 1}$ & $\mathbf{1 . 0 1}$ & $\mathbf{1}$ & $\mathbf{1}$ & $\mathbf{1}$ & $\mathbf{1}$ & $\mathbf{0 . 1 2 6 7 5 7 9}$ \\
1.02 & 1.02 & 1 & 1 & 1 & 1 & 0.1268772 \\
1.03 & 1.03 & 1 & 1 & 1 & 1 & 0.1270015 \\
1.04 & 1.04 & 1 & 1 & 1 & 1 & 0.1271312 \\
1.05 & 1.05 & 1 & 1 & 1 & 1 & 0.1272669 \\
1.06 & 1.06 & 1 & 1 & 1 & 1 & 0.1274091 \\
\hline
\end{tabular}

Berdasarkan Tabel 2, diperoleh nilai GCV terkecil sebesar 0.1267579 untuk titik knot pertama nilainya pada $X_{1}=X_{2}=1.01$ dan $X_{3}=1$ sedangkan pada titik knot kedua nilainya pada $X_{1}=X_{2}=X_{3}=1$. Berdasarkan titik knot optimal pada Tabel 3, diperoleh estimasi parameter untuk $m=1$ dengan 2 titik knot adalah sebagai berikut:

$$
\begin{aligned}
\hat{y}_{i}= & -0.078+0.0838 x_{1 i}+0.9766\left(x_{1 i}-1.01\right)_{+}^{1}-0.0691\left(x_{1 i}-1\right)_{+}^{1}-37.0181 x_{2 i}+0.0236\left(x_{2 i}-1.01\right)_{+}^{1} \\
& +0.3058\left(x_{2 i}-1\right)_{+}^{1}+36.9165 x_{3 i}+0.0236\left(x_{3 i}-1\right)_{+}^{1}+0.3058\left(x_{3 i}-1\right)_{+}^{1}
\end{aligned}
$$

Tabel 3. Nilai GCV Spline Multivariabel untuk $m=2$ dengan 2 Titik Knot

\begin{tabular}{ccccccc}
\hline & Titik Knot ke-1 & \multicolumn{3}{c}{ Titik Knot ke-2 } & \multirow{2}{*}{ GCV } \\
\cline { 1 - 5 } X1 & $\mathbf{X 2}$ & $\mathbf{X 3}$ & $\mathbf{X 1}$ & $\mathbf{X 2}$ & $\mathbf{X 3}$ & \\
\hline 0.08 & 0 & 0 & 0.08 & 0 & 0 & 0.1727516 \\
0.09 & 0 & 0 & 0.09 & 0 & 0 & 0.1727256 \\
$\mathbf{0 . 1}$ & $\mathbf{0}$ & $\mathbf{0}$ & $\mathbf{0 . 1}$ & $\mathbf{0}$ & $\mathbf{0}$ & $\mathbf{0 . 1 7 2 6 9 9 7}$ \\
0 & 0 & 0 & 0 & 0 & 0 & 0.1729616 \\
0.01 & 0 & 0 & 0 & 0.01 & 0 & 0.2344619 \\
0.02 & 0 & 0 & 0 & 0.02 & 0 & 0.2340674 \\
0.03 & 0 & 0 & 0 & 0.03 & 0 & 0.2336641 \\
\hline
\end{tabular}


Berdasarkan Tabel 3, nilai GCV spline multivariabel untuk $m=3$ dengan 2 titik knot sebesar 0.1726997. Titik knot pertama untuk masing-masing variabel bernilai $\mathrm{X}_{1}=0.1$ dan $\mathrm{X}_{2}=\mathrm{X}_{3}=0$, pada titik knot kedua nilai setiap variabel sama dengan knot pertama. Hasil estimasi parameter model spline multivariabel untuk $m=2$ dengan 2 titik knot optimal berdasarkan Tabel 3 adalah sebagai berikut:

$$
\begin{aligned}
\hat{y}_{i}= & -0.3452-0.1843 x_{1 i}-0.2597\left(x_{1 i}-0.1\right)_{+}^{1}+1.6907 x_{1 i}^{2}+1.7968\left(x_{1 i}-0.1\right)_{+}^{2}+0.0109 x_{2 i}-0.5757\left(x_{2 i}-0\right)_{+}^{1} \\
& +0.1486 x_{2 i}^{2}-1.0453\left(x_{2 i}-0\right)_{+}^{2}+0.3214 x_{3 i}+0.1486\left(x_{3 i}-0\right)_{+}^{1}-1.0453 x_{3 i}^{2}+0.3214\left(x_{3 i}-0\right)_{+}^{2}
\end{aligned}
$$

didapatkan R-square $=0.8246$ dan $\mathrm{MSE}=0.1681$

\section{Kesimpulan}

Langkah awal pemodelan regresi nonparametrik dengan metode spline adalah menentukan nilai knot optimal. Penentuan knot optimal dilakukan untuk masing-masing orde, yaitu $m=1$ (linier) dan $m=2$ (kuadratik) di setiap knot. Nilai GCV terkecil merupakan titik knot optimal. Pada pemodelan inflasi spline multivariabel $m=1$ dan $m=2$ untuk 1 titik knot dan 2 titik knot, didapat nilai R-square tertinggi pada $m=2$ dengan 1 titik knot yaitu sebesar $93.94 \%$. Modelnya adalah sebagai berikut:

$$
\begin{aligned}
\hat{y}_{i}= & -0.469+0.029 x_{1 i}-0.044\left(x_{1 i}-1.1\right)_{+}^{1}+0.894 x_{1 i}^{2}-0.044\left(x_{1 i}-1.1\right)_{+}^{2}+0.894 x_{2 i}+0.976\left(x_{2 i}-1\right)_{+}^{1} \\
& -0.256 x_{2 i}^{2}+0.2901\left(x_{2 i}-1\right)_{+}^{2}+0.0921 x_{3 i}-4.425\left(x_{3 i}-1\right)_{+}^{1}-0.0455 x_{3 i}^{2}-4.425\left(x_{3 i}-1\right)_{+}^{2}
\end{aligned}
$$

dengan R-Square $=0.9394$ dan MSE $=0.0581$.

Berdasarkan model tersebut, variabel-variabel perubahan harga beras, daging ayam, cabai rawit, dan tanaman sayur memberikan kontribusi terhadap nilai inflasi sebesar $93.94 \%$.

\section{DAFTAR PUSTAKA}

1. Budiantara, I.N., Metode U, GML, CV, dan GCV dalam regresi Nonparametrik Spline, Majalah Ilmiah Himpunan Matematika Indonesia (MIHMI), 2000, Vol. 6: 285290.

2. Erifandi, W., Estimator Spline Parsial dalam Regresi Semiparametrik Multirespon, Tesis Magister Statistika Institut Teknologi Sepuluh Nopember, Tidak dipublikasikan.

3. Eubank, R.L., Spline Smoothing and Nonparametric Regression, Marcel Dekker, New York, 1988.

4. Hardle, W., Applied Nonparametric Regression, Cambridge University Press, NewYork. 1990

5. Siregar, R.Y., and Goo, S., Effectiveness and Commitment to Inflation Targeting Policy: Evidence from Indonesia and Thailand, Journal of Asian Economics, 2010, Vol. 21: 113-128.

6. Suparti . Analisis Data Inflasi di Indonesia Menggunakan Model Regresi Spline, Jurnal Media Statistika, 2013, Vol. 6, No. 1.

7. Wahba, G., Spline Smoothing Models With Correlated Errors, Journal of the American Statistical Association, 1990, Vol. 93: 341-348

8. Wang, Y., Spline Smoothing Models with Correlated Errors, Journal of The American Statistical Association, Vol. 93: 341-348

9. Wimanda, R.E., Turner, P.M., and Hall, M.J.B., Expextions and The Inertia of Inflation: The Case of Indonesia, Journal of Policy Modeling, 2011, Vol. 22: 426-438. 